\title{
CUI BONO? - CURRICULARIZAÇÃO DA EXTENSÃO COM COMUNIDADES DE AGRICULTURA FAMILIAR SEM ÁGUA POTÁVEL
}

\author{
Bianca Dias Moreira - biancadias454@gmail.com \\ Universidade Estadual de Feira de Santana, Colegiado de Engenharia Civil \\ Pablo Rodrigo Fica Piras - pafipi@uefs.br \\ Universidade Estadual de Feira de Santana, Departamento de Tecnologia \\ Avenida Transnordestina $s / n$, Módulo 3 \\ 44036-900 - Feira de Santana - Bahia
}

\begin{abstract}
Resumo: A partir do Plano Nacional de Educação, os cursos de Engenharia estão incumbidos de dedicar, até 2024, pelo menos $10 \%$ da sua carga horária em extensão universitária, cuja efetivação é um desafio não menor para as instituições. Tendo como foco da sua atuação a execução da tríade universitária ensino-pesquisa-extensão, os grupos do Programa de Educação Tutorial vêm convergindo com sua prática equilibrada, acostumados a transpor os muros institucionais e a estabelecer contatos com setores da Sociedade. $O$ quadro aqui relatado mapeia um conjunto de comunidades de diferentes municípios do interior baiano, onde faltam, simultaneamente, água potável e eletricidade, o que torna impraticável a geração de renda mediante o processamento dos produtos da agricultura familiar. Além do apontamento destes locais, a atividade tutorial focou-se na estimativa da estrutura e esforços necessários para os pré-projetos de instalações de geração de energia fotovoltaica e de perfurações de poços, em cada uma dessas localidades, como proposta técnico-econômica para proporcionar condições à produção local. Os dados foram retirados de um cadastro realizado em 2018 pela Companhia de Desenvolvimento e Ação Regional $(C A R)$, que contêm acima de 1100 empreendimentos que tiveram sua implantação interrompida. Os autores entendem que este procedimento, que pode ser continuado $e$ aprofundado nestas ou outras hipossuficiências, reveladas em outros cadastros, é uma oportunidade cumprir com a lei mencionada em todos os cursos de engenharia da instituição.
\end{abstract}

Palavras-chave: Poços d'água. Energia fotovoltaica. Mapeamento. Programa PET/MEC. 


\title{
每一次漫长的步行都从第一步开始 \\ toda longa caminhada começa pelo primeiro passo \\ Mao Tsé-Tung
}

\section{INTRODUÇÃO}

O papel da extensão está em evolução. Citando o escritor Boaventura de Souza Santos:

\begin{abstract}
"A área de extensão vai ter no futuro próximo um significado muito especial. No momento em que o capitalismo global pretende funcionalizar a Universidade e, de facto, transformá-la numa vasta agência de extensão ao seu serviço, a reforma da Universidade deve conferir uma nova centralidade às atividades de extensão (com implicações no curriculum e nas carreiras dos docentes) e concebê-las de modo alternativo ao capitalismo global, atribuindo às Universidades uma participação activa na construção da coesão social, no aprofundamento da democracia, na luta contra a exclusão social e a degradação ambiental, na defesa da diversidade cultural" (FORPROEX, 2012).
\end{abstract}

Consequente com a demanda do FORPROEX, dois anos depois foi publicado o Plano Nacional de Educação, que na sua meta 12.7) determina a inclusão de pelo menos $10 \%$ da carga horária obrigatória dos cursos de educação superior dedicada a questões próprias da extensão universitária (BRASIL, 2014). A efetiva realização desta meta tem se tornado um desafio relevante para as instituições, pouco acostumadas a praticá-la.

Chamados para cumprir a tríade universitária ensino-pesquisa-extensão de forma indissociável, os grupos do Programa de Educação Tutorial devem procurar convergir a essa prática, transpondo os muros institucionais e estabelecendo contatos com diversos setores da Sociedade.

As formas de estabelecer o contato são naturalmente diversificadas. Neste particular, nos seus nove anos de trajetória, o grupo PET Engenharias tem desenvolvido a metodologia de entrar em contato com uma determinada comunidade de agricultura familiar primeiro e, depois do mútuo conhecimento e abordagem dialógica da realidade concreta do local, converge para uma definição conjunta das demandas mais relevantes, vinculadas às tecnologias que elas manifestam necessitar para incorporar à produção e gerar renda, na tentativa de aproximar-se mais ao bem-viver. Este procedimento já vem sendo trilhado com relativo sucesso e apresentado em trabalhos anteriores (SENA et alii, 2018; OLIVEIRA et alii, 2018; MOTA et alii, 2019; QUEIROZ et alii, 2020; MACHADO et alii, 2020), onde o trajeto nos seus nove anos de existência tem mantido como focos a "Segurança Alimentar e Inclusão Digital de comunidades de agricultura familiar do semiárido baiano", considerando que naturalmente pertencem a este escopo de atuação tanto a introdução de tecnologias para possibilitar a reprodução material da permanência na terra tradicional, mediante a geração de renda das comunidades de agricultores. $\mathrm{O}$ escopo de atividades tem sido diversificado, tanto em áreas de atuação como em abrangência territorial, em diferentes pontos do Estado da Bahia.

Mas este procedimento está naturalmente limitado pelo alcance dos contatos trazidos ao Grupo pelos próprios membros ou por equipes de pesquisa/extensão, da própria instituição ou de organizações outras, que proponham convergência na práxis. Também apresenta limitações quando à sintonia com os conceitos e realidades próprias das políticas públicas, entendidas como iniciativas do Estado, sistêmicas, a serem aplicadas visando a solução das dificuldades 
enfrentadas na sociedade "voltadas, em princípio, para a redistribuição dos benefícios sociais visando a diminuição das desigualdades estruturais produzidas pelo desenvolvimento socioeconômico" (HÖFLING, 2001).

Assim, o presente trabalho propõe a iniciação do ciclo extensionista com uma sistemática invertida, diferente da que costumeiramente vem sendo realizada, proporcionando mais protagonismo à demanda das comunidades do que às vontades espontâneas existentes no grupo ou na instituição, entendendo que o foco de participação ativa proposto por Boaventura Santos se concretiza na construção de propostas junto com a sociedade, contra a exclusão social e na defesa da diversidade cultural, entre outros elementos convergentes (FORPROEX, 2012; GOMES, 2017).

\section{PET, EXTENSÃO E COMUNIDADE}

\subsection{Trajetória extensionista do PET Engenharias}

Composto por discentes e egressos dos quatro cursos de engenharia da UEFS (Engenharia Agronômica, Engenharia Civil, Engenharia de Alimentos e Engenharia de Computação), este grupo PET desenvolve atividades extensionistas mormente em mais de vinte municípios baianos (Água Fria, Banzaê, Caém, Cansanção, Capim Grosso, Conceição do Coité, Euclides da Cunha, Feira de Santana, Irará, Itiúba, Licínio de Almeida, Monte Santo, Quijingue, Quixabeira, Ruy Barbosa, Salinas da Margarida, Santa Bárbara, Uauá, Umburanas, Utinga e Wagner). Os interlocutores destas atividades pertencem a comunidades de agricultura familiar, que incluem aldeias, quilombos, fundos-de-pasto, agrupados ou não em associações e cooperativas. Tem ocorrido contatos com autoridades municipais (prefeitos, secretários, assessores), mas o mais comum é termos nos aproximado através de lideranças comunitárias.

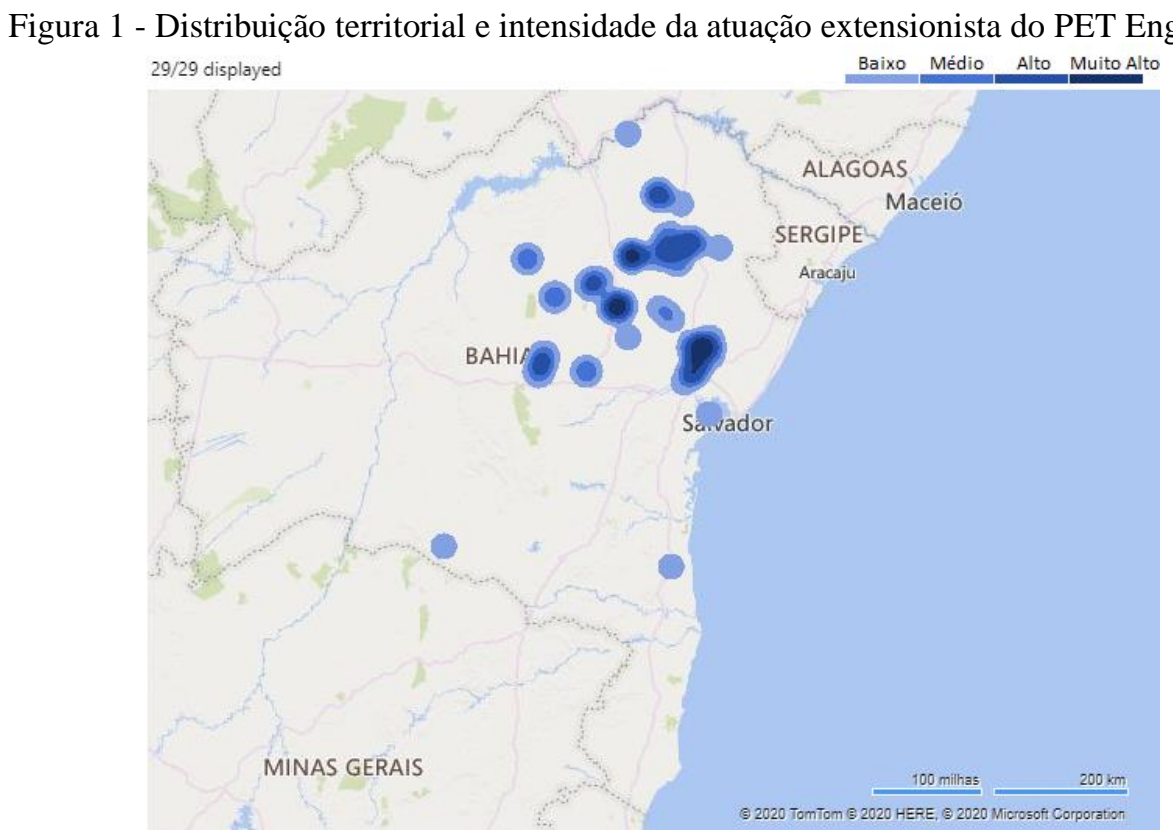

Fonte: Própria autoria

A intensidade do contato em geral redunda também em um maior avanço nas realizações. Assim, há casos de ainda mútuo conhecimento apenas, com propostas para serem desenvolvidas a futuro, com realizações já finalizadas ou detidas por falta de financiamento, e casos em que o Grupo tem submetido propostas que foram contempladas, inclusive em mais 
de um Edital de financiamento para construção de (FICA PIRAS e SENNA, 2015; SOUZA et alii, 2017).

Uma visualização da distribuição territorial e intensidade da atuação extensionista do PET Engenharias, levando em conta a intensidade mencionada acima, pode ser vista na Figura 1 .

A atividade do PET Engenharias junto às diferentes comunidades das localidades tem sido diversificada, distribuída em: produtos de origem vegetal (caju, acerola, umbu, licuri, mandioca, hortaliças, PANCs), produtos de origem animal (mel, laticínios, aves de corte, bode, carneiro, mariscos), disponibilização e tratamento d'água (água subterrânea e dessalinização) e outras tarefas diversificadas vinculadas com as anteriores, tais como defesa da posse da terra, inclusão digital, artesanato, automação da irrigação. Uma visualização da abrangência territorial dessas ações está representada na Figura 2.

Figura 2 - Distribuição territorial e tipo de atuação extensionista do PET Engenharias

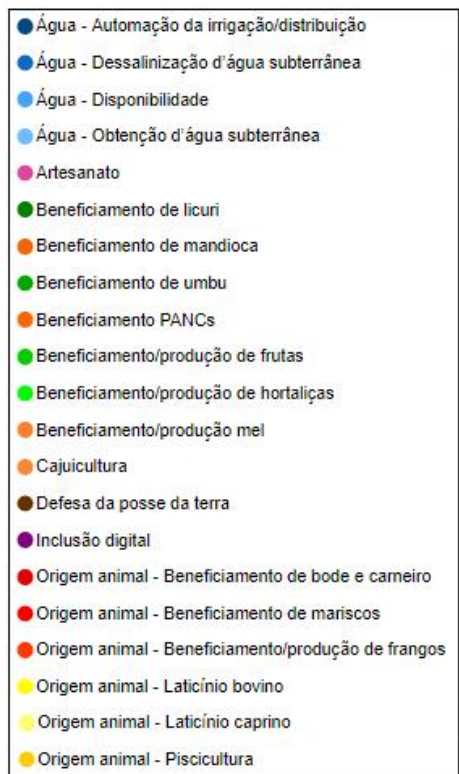

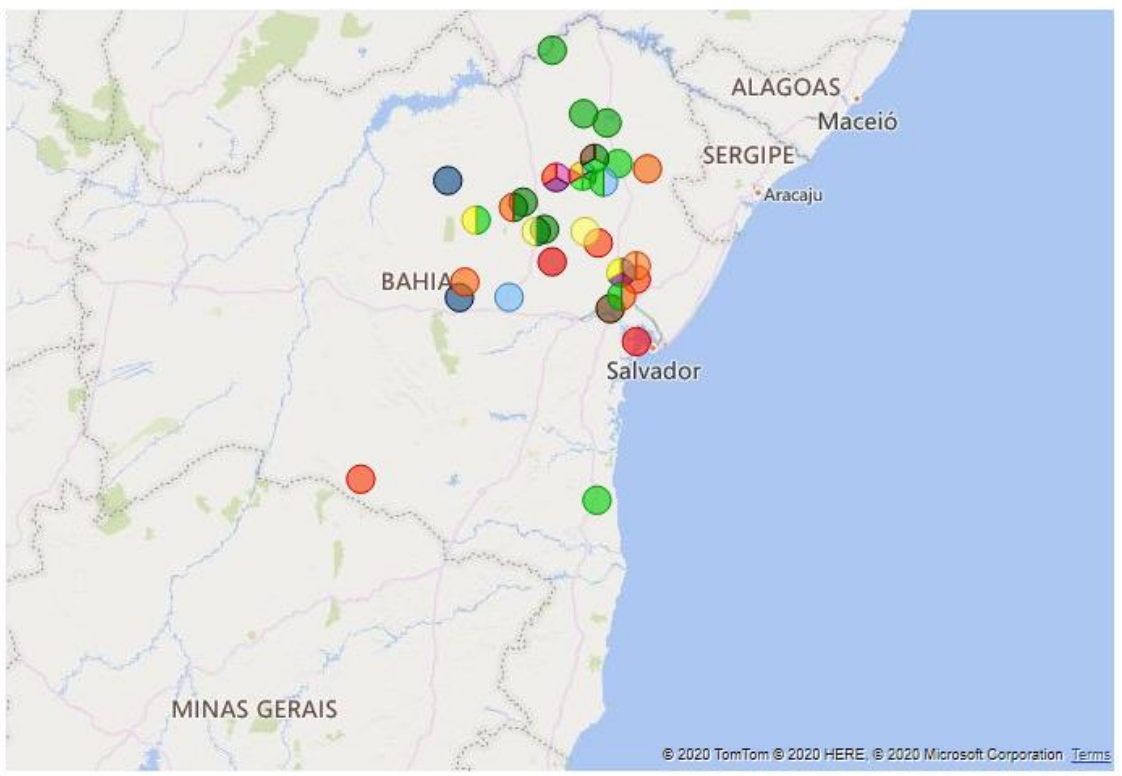

Fonte: Própria autoria

\subsection{Comunidades do semiárido sem água potável nem energia}

Conforme levantamento feito em 2018 pela Companhia de Desenvolvimento e Ação Regional (CAR) mais de 1100 empreendimentos (associações e cooperativas) de estruturas de produção da agroindústria familiar na Bahia tiveram sua implementação interrompida, fazendo-se necessário definir melhor o que pode ser feito para resgatar a estrutura e comunidade no seu entorno. Esses empreendimentos estão distribuídos em quase 300 municípios baianos, espalhados pelos 27 territórios da Bahia.

Dessas unidades de agricultura familiar, 43 apresentam problemas de estrutura que impedem o funcionamento por falta de ligação elétrica e 25 por falta de ligação de água. Essas 68 associações estão distribuídas em 53 municípios baianos (Alcobaça, América Dourada, Andaraí, Angical, Antônio Gonçalves, Araci, Banzaê, Barra do Mendes, Boa Nova, Boninal, Buritirama, Camamu, Canavieiras, Casa Nova, Coaraci, Cotegipe, Encruzilhada, Entre Rios, Eunápolis, Gongogi, Guaratinga, Ibiassucê, Ibipeba, Ibotirama, Ichu, Igrapiúna, Ipirá, Irará, Itaeté, Itagi, Itapitanga, Jaguarari, Morpará, Morro do Chapéu, Mortugaba, Mundo Novo, Nordestina, Nova Fátima, Nova Ibiá, Pé de Serra, Piatã, Pindaí, Portiraguá, Riachão do Jacuípe, Ribeirão do Largo, Santa Rita de Cássia, Santa Terezinha, Santanópolis, Tanque 
Novo, Várzea da Roça, Vitória da Conquista, Wanderley e Xique-Xique), sendo alguns desses locais de atuação do grupo PET Engenharias da UEFS.

As Figuras 3 e 4 apontam a distribuição desses municípios pelo território baiano por meio de mapas de calor, onde a distância do município em questão até a cidade de Feira de Santana é fator determinante do diâmetro da bolha e da cor da mesma, ou seja, quanto mais distante da cidade de Feira de Santana, maior e mais escura será a bolha.

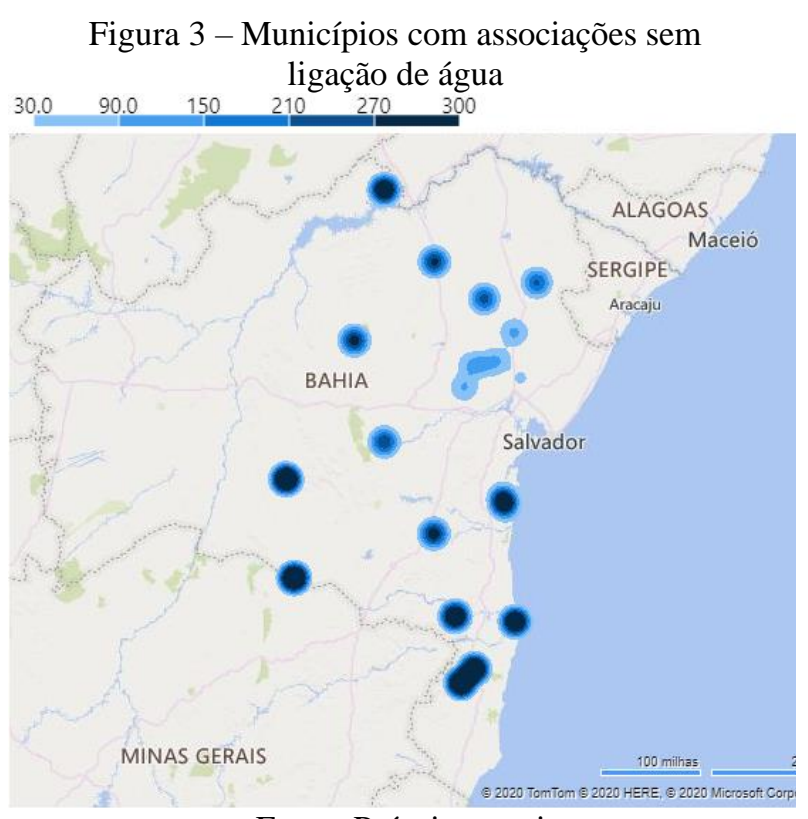

Fonte: Própria autoria
Figura 4 - Municípios com associações sem ligação elétrica

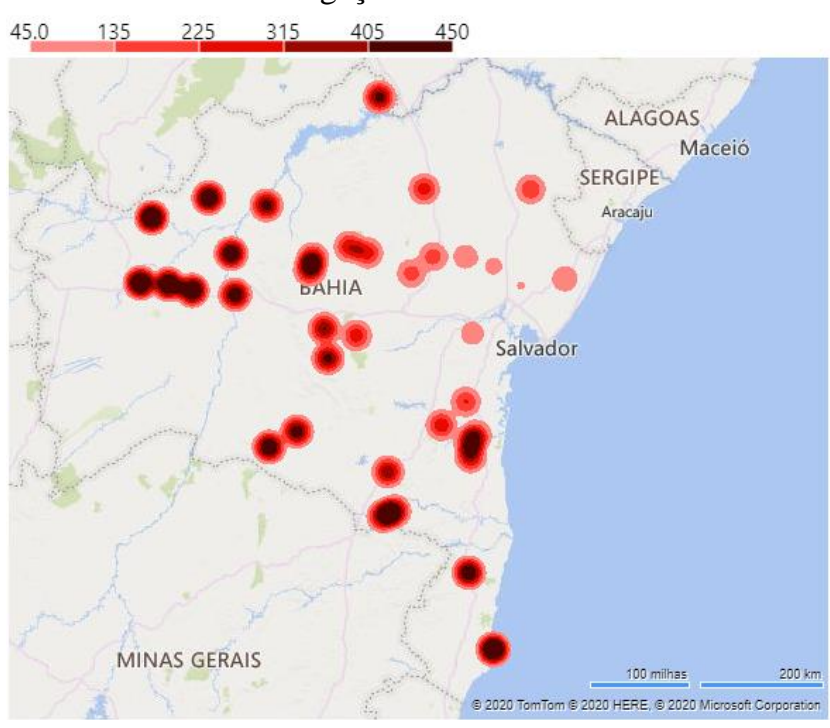

Fonte: Própria autoria

\subsection{Elementos de pré-projeto para disponibilidade d'água}

\section{Perfuração de poços e bombeamento d'água subterrânea}

De acordo com CEI/SEPLANTEC (1991, apud MAIA, RODRIGUES, SOUZA, 2013), a seca é recorrente no clima semiárido, o qual predomina em boa parte da Bahia. Devido à extensão territorial e atuação de diversos sistemas meteorológicos, esse estado é constantemente atingido pela escassez da água. Essa seca provoca um desequilíbrio entre a oferta e a demanda por recursos hídricos.

É nesse cenário que a perfuração de poços para aproveitamento d'água subterrânea vem ganhando força. Segundo dados da base do CPRM (2019), são vinte e sete mil duzentos e trinta e um (27.231) poços d'água registrados pelo Serviço de Informação de Águas Subterrâneas - SIAGAS no estado da Bahia.

Quando a perfuração de um poço se dá num aquífero não-confinado, tem-se um poço comum onde é necessário a utilização de bomba para a retirada da água. O chamado poço artesiano é aquele que foi perfurado num aquífero confinado e que não necessita de energia para bombear água pois a pressão d'água confinada é suficiente para fazê-la jorrar.

A escolha da bomba para a retirada da água de poços comuns deve ser feita com base nas características do poço em questão e da finalidade da utilização da água. De uma forma geral, as informações necessárias para dimensionar a bomba são: profundidade da instalação da bomba, comprimento total da tubulação de recalque, altura de recalque, nível estático e dinâmico do poço, profundidade total do poço, distância mínima do fundo do poço, diâmetro e vazão do poço.

O cálculo da potência da bomba necessária para retirar a água do poço pode ser feito utilizando a equação a seguir. 


$$
P O T=\frac{\gamma \cdot Q \cdot H}{75 \cdot \eta}
$$

Sendo,

POT: potência consumida pela bomba $[\mathrm{CV}]$;

$\gamma:$ peso específico do fluido $\left[\mathrm{kgf} / \mathrm{m}^{3}\right]$;

$Q:$ Vazão $\left[\mathrm{m}^{3} / \mathrm{s}\right]$

$H$ : Carga $[\mathrm{m}]$;

$\eta$ : Rendimento da bomba.

\section{Geração de energia fotovoltaica}

Mesmo com uma diversidade de fontes energéticas à disposição, a matriz energética mundial é composta, principalmente, por petróleo e seus derivados, carvão e gás natural, que são fontes de energia não renováveis. Esse grupo correspondia cerca de $81,1 \%$ da matriz energética mundial em 2016, enquanto as fontes renováveis totalizavam 14\% (IEA, 2018). Dentro desse grupo de fontes renováveis podem ser citadas a solar, eólica, geotérmica, hidráulica e de biomassa.

No Brasil, entretanto, apesar do consumo de energia oriunda de fontes não renováveis ser superior do que das fontes renováveis, o uso dessa última citada é alta quando comparada ao restante do mundo. De acordo a Resenha Energética Brasileira de maio de 2019, publicada pelo Ministério de Minas e Energia, a matriz energética brasileira era dividida em 54,7\% de energias não renováveis e 45,3\% de energias renováveis.

É indiscutível que, por serem fontes não renováveis, os combustíveis fósseis vão se esgotar no planeta. Além do mais, os danos causados ao meio ambiente e à população pelo uso desses combustíveis têm gerado discussões a nível global acerca do investimento e da implementação das fontes de energia renováveis que se mostram imprescindíveis.

A geração de eletricidade por meio da energia solar foi evidenciada em 1839 pelo físico francês Edmond Becquerel, ao colocar duas placas de latão imersas em um eletrólito líquido e expor ao sol. A esse fenômeno deu-se o nome de efeito fotovoltaico. Desde o desenvolvimento da primeira célula solar preparada a base de silício por cientistas da Bell Labs em 1954, as pesquisas no ramo não pararam mais (MACHADO, MIRANDA, 2015). Entretanto, essa fonte de energia ainda não é utilizada em grande escala devido ao seu custo de investimento elevado.

Parte da radiação solar que atinge o topo da atmosfera é absorvida pelos gases presentes na mesma, porém uma grande parte ultrapassa a atmosfera e pode ser aproveitada como fonte de energia. No Brasil, o índice de irradiação solar é alto quando comparado à outros países, em certos estados a média anual fica entre 5900 e $6100 \mathrm{Wh} / \mathrm{m}^{2}$, como é possível verificar na Figura 5.

A unidade fundamental do processo de geração de eletricidade a partir da energia solar é a célula fotovoltaica, pois é nela que se dá o efeito fotovoltaico (MATAVELLI, 2013). As células são feitas de materiais semicondutores, como por exemplo o silício, porém, esse elemento sozinho não é capaz de gerar eletricidade em níveis satisfatórios quando exposto a luz solar. Para alcançar níveis elevados de corrente elétrica, o silício passa pelos processos de dopagem do tipo $\mathrm{p}$ e do tipo $\mathrm{n}$, onde é acrescido outros elementos químicos como, por exemplo, o boro e o fósforo (MACHADO; MIRANDA, 2015).

As células fotovoltaicas, individualmente, não conseguem gerar tensão suficiente para alimentar cargas habituais, porém, conectando-as em série tem-se uma geração de tensão em uma ordem superior. Essa ligação em séries das células dá origem ao módulo fotovoltaico. 
Esses ainda podem ser associados (em série, paralelo ou misto) para formar os painéis fotovoltaicos.

De acordo CRESESB (2016) "um sistema fotovoltaico pode ser classificado em três categorias distintas: sistemas isolados, híbridos e conectados à rede". Nos sistemas isolados, geralmente, há o uso de elementos que possam armazenar energia, como por exemplo baterias. Nos sistemas híbridos têm-se várias fontes de geração de energia, como por exemplo, turbinas eólicas, geração diesel, módulos fotovoltaicos, entre outros. Já o sistema conectado à rede não utiliza elementos de armazenamento de energia pois a geração é entregue diretamente a rede.

Para sistemas fotovoltaicos conectados à rede ou que alimentam os aparelhos das residências, é necessário o uso de um inversor, pois os aparelhos operam com corrente alternada, e a corrente gerada pela energia solar é do tipo contínua. De acordo Lazzarin (2010), inversores "são estruturas que alimentam cargas com correntes alternadas (CA) a partir de uma fonte de corrente contínua (CC)".

Figura 5 - Mapa da média anual de radiação solar $\left(W h / m^{2}\right)$

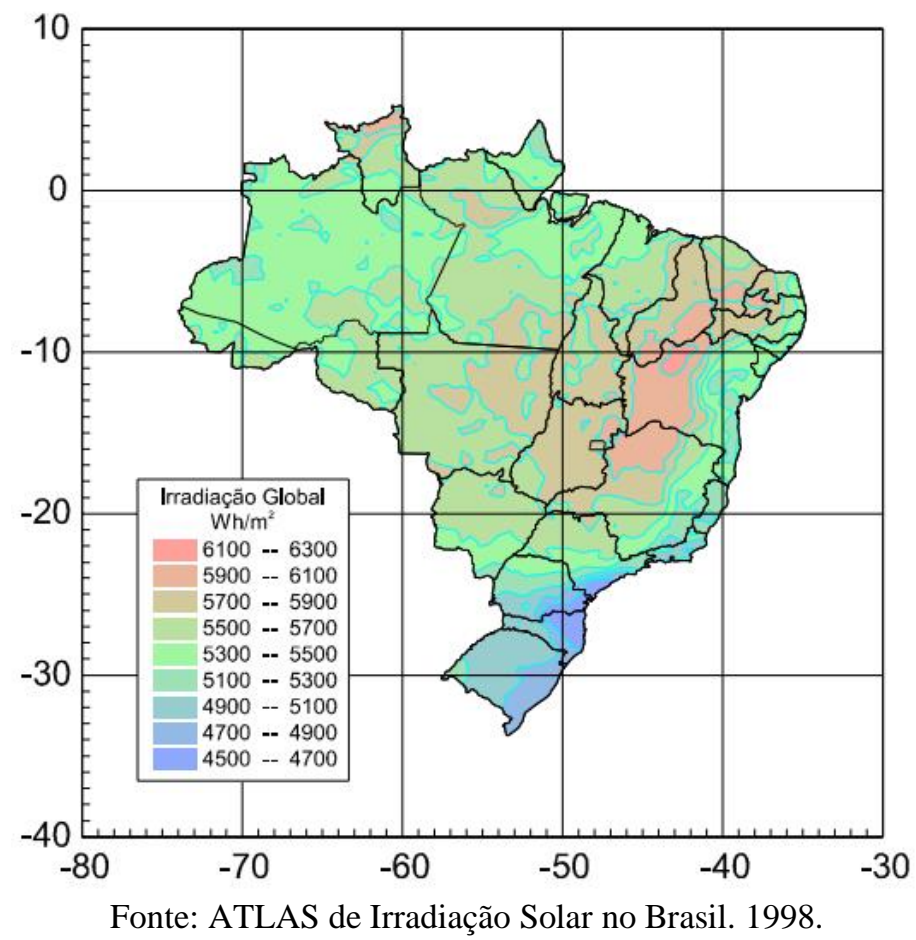

Habitualmente, a água subterrânea é extraída através do uso de bomba elétrica, que têm os seus sistemas abastecidos com combustível diesel. Porém, esses sistemas exigem uma manutenção regular para garantir o funcionamento satisfatório, que não é barata, além do gasto com a compra de combustível e a poluição causada pela emissão de dióxido de carbono. É nesse cenário que surgem novas formas de acionamento da bomba. O bombeamento de água solar, ou bombeamento de água fotovoltaico (PVP) é uma dessas alternativas.

De acordo Chilundo, Neves e Mahanjane (2019), a tecnologia solar fotovoltaica tem sido, nas últimas décadas, uma das formas mais populares de aplicação de energia solar para sistemas de bombeamento de água. A utilização da energia fotovoltaica para o acionamento de bombas de água é uma solução alternativa, pois eletricidade gerada não prejudica o meio ambiente, por ser uma fonte renovável, e beneficia locais onde não há a disponibilidade de energia proveniente da rede (DRISSI et al, 2017; MATAM et al, 2018). 
Podem ser utilizados dois tipos de sistemas fotovoltaicos independentes: o primeiro utiliza uma bateria que armazena a energia fotovoltaica excedente, porém, esse sistema tem um custo mais elevado, podendo ter um aumento de 10 a 50\% (BHENDE, MALLA, 2012); o segundo não utiliza bateria para armazenar energia, ao invés disso, a água bombeada é armazenada em um tanque (SONTAKE, KALAMKAR, 2016).

Com a bomba devidamente dimensionada é possível calcular o quanto de energia deve ser gerado pelo sistema fotovoltaico para o acionamento da bomba, para então calcular quantos módulos fotovoltaicos deverão ser utilizados.

Pela equação (1) tem-se a potência da bomba em Cavalo-vapor (CV), porém, no sistema internacional (SI) de unidades de medidas, a potência é descrita em Watt (W) e as especificações dos módulos fotovoltaicos seguem esse padrão, assim sendo, é necessário fazer essa conversão da potência necessária da bomba em CV para W. Essa conversão é feita usando a proporção $1 \mathrm{CV}=735,499 \mathrm{~W}$.

Tendo em mãos a potência em Watt que a bomba requer para funcionar, basta escolher a quantidade de módulos fotovoltaicos adequados para atender essa demanda analisando a potência dos mesmos, especificada pelo fabricante.

\section{Dessalinização d'água salobra}

Não seria uma surpresa que em alguma das localidades a água disponível, além de subterrânea seja salobra. Isso não deve desanimar. As regiões do mundo que corriqueiramente já vem utilizando a dessalinização d'água do mar como forma de obter água potável, mesmo quando dispõem de combustíveis fósseis em abundância, estão pesquisando a possibilidade de usufruir de energias alternativas e diminuir os custos de produção. Não entra nestas expectativas somente a energia solar, embora ela seja de fato a mais abundante no mundo. Em um trabalho de simulação computacional, que considerou uma planta híbrida que inclui destilação de múltiplos efeitos e dessalinização por osmose reversa, uma planta de produção de água doce foi projetada e otimizada a partir de trabalhos precedentes. Como resultado, contemplado o financiamento das estações, a água assim produzida fica por volta de $R \$ 3 / \mathrm{m}^{3}$ em média nas cidades analisadas: Isola di Pantelleria (Itália), Las Palmas (Espanha), Abu Dhabi (Emirados Árabes Unidos) e Perth (Austrália), mais caros que em estações tributárias da energia eólica, mais baratos que a energia elétrica usual em cada localidade, de valores entre $R \$ 0,25$ e $R \$ 1,25 / k W h$ (FILIPPINI et alii, 2019). Algumas das poucas instalações que estão em operação no sertão baiano, do Programa PAD, administradas pelas associações ou prefeituras, cobram por volta $\mathrm{R} \$ 1$ pelos dez litros.

\section{CONSIDERAÇÕES FINAIS}

Através do levantamento das 68 possibilidades de atuação aqui apresentadas, especificamente na disponibilização d'água para comunidades de 53 municípios da Bahia, podem ser extrapoladas as diversas modalidades de assistência técnica que podem vir a ficar em evidência como necessárias, ao tempo que ocorre a imersão dos futuros egressos na realidade concreta dos campos mais preteridos da atuação profissional, assim como a legitimação do papel social da universidade, oferecendo à sociedade engenheiros formados com estas vivências na sua formação. 


\section{REFERÊNCIAS}

BHENDE, C. N.; MALLA, S. G. Novel control of photovoltaic based water pumping system without energy storage. International Journal of Emerging Electric Power Systems, v. 13, n. $5,2012$.

BRASIL. Lei $\mathbf{n}^{0}$ 13.005, de 25 de junho de 2014, que aprova o Plano Nacional de Educação - PNE. 2014. Disponível em:

http://www.planalto.gov.br/ccivil_03/_ato2011-2014/2014/lei/113005.htm. Acesso em 02 fevereiro 2020.

CAR/SDR. Relatório dinâmico do cadastro da agroindústria familiar. Comunicação pessoal. 20 pág. 2018.

CHILUNDO, R. J.; NEVES, D.; MAHANJANE, U. S. Photovoltaic water pumping systems for horticultural crops irrigation: Advancements and opportunities towards a green energy strategy for Mozambique. Sustainable Energy Technologies and Assessments 33, p. 61-68. 2019.

CPRM - SERVIÇO GEOLÓGICO DO BRASIL. Sistemas de Informação de Águas Subterrâneas - SIAGAS. Disponível em:

http://siagasweb.cprm.gov.br/layout/pesquisa_complexa.php. Acesso em: 29 jul. 2020.

CRESESB. Energia Solar: Princípios e aplicações. 2006.

DRISSI, H. et al. Critical factors affecting the photovoltaic characteristic and coparative study between two maximum power point tracking algorithms. Hydrogen Energy 42 (13), p. 8689-8702. 2017.

FICA-PIRAS, P. R., SENNA, D. O.. A agricultura familiar do semiárido baiano como universo extensionista da formação de engenheiros. XLIII COBENGE. São Bernardo do Campo. 2015.

FILIPPINI, G. et alii. Design and economic evaluation of solar-powered hybrid multi effect and reverse osmosis system for seawater desalination. Desalination 465:114-25. 2019.

FORPROEX. Política Nacional de Extensão Universitária. Manaus, 2012. Disponível em: https://proex.ufsc.br/files/2016/04/Pol\%C3\%ADtica-Nacional-de-Extens\%C3\%A3oUniversit\%C3\%A1ria-e-book.pdf. Acesso em 02 fevereiro 2020.

GOMES, L.F et alii. Engenharia pública para a curricularização da extensão no semiárido baiano. In: XVI ENEPET, Teresina, Piaui. Apresentação de Pôster, UFPI, 2017.

HOFLING, E.M.. Estado e Políticas (Públicas) Sociais. Cadernos CEDES, Campinas 21(55):30-41, nov. 2001. Disponível em: https://www.scielo.br/scielo.php?script=sci_arttext\&pidS010132622001000300003\&lng=pt\&tlng=pt . Acesso em: 27 jul. 2020

IEA - International Energy Agency. Explore energy data by category, indicator, country or region. Disponível em: https://www.iea.org/data-andstatistics?country=WORLD\&fuel=Energy\%20supply\&indicator=Coal\%20production $\%$ 20by\%20type. Acesso em: 29 jul. 2020.

LAZZARIN, Telles Brunelli. Paralelismo de inversores de tensão. 2010. 319 f. Tese (Pósgraduação) - Universidade Federal de Santa Catarina, 2010.

MACHADO, C. T; MIRANDA, F, S. Energia Solar Fotovoltaica: Uma Breve Revisão. Revista Virtual de Química, v.7, n.1, p. 126-143, 2014.

MAIA, P. H. P.; RODRIGUES, R. S.; SOUZA, N.. Estratégias para ampliar a oferta de Água no Semiárido Baiano. Cadernos de Geociências, V. 10, n. 2, p. 116-132, 2013.

MATAM, M., et al. Optimized Reconfigurable PV array based Photovoltaic water-pumping system. Sol. Energy 170 (November 2017), p. 1063-1073. 2018. 
MATAVELLI, Augusto Cesar. Energia solar: geração de energia elétrica utilizando células fotovoltaicas. 2013. 34 f. Monografia - Escola de Engenharia de Lorena, Universidade de São Paulo, 2013.

MME - Ministério de Minas e Energia. Resenha Energética Brasileira. 2019.

MOTA, R.S. et alii. Atividade extensionista: metodologia de identificação de barragens e aguadas no semiárido baiano, uma aplicação em Santa Bárbara (BA). In: XXIV Encontro Nacional dos Grupos do Programa de Educação Tutorial, 2019, Natal. Anais. UFRN, 2019. pág. 311-22. 2019.

OLIVEIRA, P.K.S. et alii. Qualificação sanitária como ingrediente do selo de origem no requeijão de Santa Bárbara. In: XIII EBAPET, Feira de Santana. Apresentação de Pôster. UEFS, 2018.

PRESS, F. et al. Para Entender a Terra. 4. Ed. Porto Alegre, Bookman, 2016.

QUEIROZ, M.V.L. et alii. Santa Bárbara e os PET/MEC UEFS em sintonia com a Agenda 2030 da ONU. Trabalho aceito no XIX ENEPET, São Luís, 2020;

SENA, A.L. et alii.. Associação e qualificação de produtores como ingrediente do selo de origem no requeijão de Santa Bárbara. In: XIII EBAPET, 2018, Feira de Santana. Apresentação de Pôster. UEFS, 2018.

SONTAKE, V. C.; KALAMKAR, V. R. Solar photovoltaic water pumping system - A comprehensive review. Renewable and Sustainable Energy Reviews. v. 59, p. 1038$1067,2016$.

SOUZA, V.S.; SILVA, J.S.; FICA PIRAS, P.R.. Construcción de un matadero comunitario de aves, como una iniciativa para el desarrollo local. VI Taller Internacional de Desarrollo Local, 28 a 30 de marzo, Universidad de Granma, Bayamo, Cuba, 2017.

\title{
CUI BONO? - EXTENSION CURRICULARIZATION WITH FAMILY AGRICULTURE COMMUNITIES UNDER DRINKING WATER UNAVAILABILITY
}

\begin{abstract}
From the National Education Plan onwards, until 2024, Engineering courses are responsible for dedicating at least $10 \%$ of their mandatory credits for university extension activities. Its implementation is being a great challenge for each institution. Focusing on the performance of the university teaching-research-extension triad, the groups in the Tutorial Education Program have been converging with their balanced practice, normally transposing institutional walls and establishing contacts with open society. This work maps a set of communities from different municipalities in the interior of Bahia, where drinking water and electricity are simultaneously lacking, which makes generating income impracticable by means of processing farming products. In addition to pointing out these locations, the tutorial activity focused on estimating the structure and efforts required for the pre-projects of photovoltaic power generation and well drilling installations, in each of these locations, as a technical-economic proposal to provide conditions for local production. The data were taken from a register carried out in 2018 by the Regional Development and Action Company $(C A R)$, which contains over 1100 projects that had their implementation interrupted. The authors understand that this procedure, which can be continued and deepened in these or other hyposufficiencies, revealed in other registers, is an opportunity to comply with the law mentioned in all engineering courses at the institution.
\end{abstract}

Keywords: Water wells. Photovoltaics. Mapping. PET/MEC Program. 